\title{
7 Developing a Linguistically Informed Approach to Police Interviewing
}

Nicci MacLeod - ORCID number 0000-0002-6642-5509

Kate Haworth - ORCID number 0000-0002-3446-8838

\section{INTRODUCTION}

This chapter focuses on discursive patterns in interactions between police interviewers (hereafter IRs) and interviewees (hereafter IEs), be the latter victims, witnesses or suspects. We describe a novel police interviewer training course we have developed and piloted under the British Association of Applied Linguistics (BAAL)'s 'Applying Linguistics' fund. We took the training package, grounded firmly in sociolinguistic theory, on the road to three English police forces. Our innovative activity takes as its point of departure the observation that the application of social scientific research has "traditionally been characterised in terms of the authority of social scientists' definitions, where the researcher possesses the expertise ... and judges the adequacy of participants' knowledge against that expertise" (Wiggins and Hepburn 2007: 290). In contrast to this, our activity focuses firstly on explicating the knowledge and skills of practitioners for the benefit of their own professional practice, highlighting areas of good practice as well as instigating a general awareness of the effects of particular discursive choices. Further to this, we involve the participants - practicing police IRs - at every stage of the process. Since language is the primary medium through which the daily working activities of organisations are conducted (Drew and Heritage 1992), it is clear that sociolinguistic research has an important role to play in the development of best practice. We hope that our efforts will encourage other sociolinguistic researchers to view the police service and similar organisations as potential sites for meaningful collaboration and engagement. 
If we take impact to mean the demonstrable outcomes of the application of social research to social problems, it is a fairly straightforward matter to categorise the activity described here as achieving impact. However, it is worth keeping in mind that many definitions of what constitutes a "social problem" are guided by political and governmental objectives (Willig 1999), rather than genuine concern for human wellbeing. In our original research projects on which this activity is based (Haworth 2009; MacLeod 2010) we were both firmly guided by a commitment to instigating the raising of awareness of sociolinguistic issues among legal and police practitioners, and, in turn, positive change in professional practices. The production of meaningful outcomes for police IRs, in turn leading to improved conditions for individuals who encounter the police, has thus been high on the agenda from the outset. Through engaging with police officers and allowing the research to be guided and adapted according to their professional requirements, our activity represents, we hope, the best method for attempts at securing human wellbeing.

It should be noted that the relationship between critical analysis and progressive practice is fraught with difficulties. As highlighted by Willig (1999), even scientific observations cannot be detached and uninvolved, and having originally taken a distinctively Critical Discourse Analytical approach to the research, it was necessary for us to adapt this approach in order to engage in a meaningful two-way process with practitioners. Thus, the approach we take here is in line with Roberts (2003), who argues that applied linguists can and should intervene, but that "we need to do it collaboratively and reflexively working with other professionals from the initial design stage through to mutual critique and evaluation” (Roberts 2003: 147).

In this chapter we discuss the relevance of various theories of language and communication to the police interview context, but more importantly the application and impact of this knowledge within the context of collaboratively designed IR training materials. We collected feedback from all our participants, and this forms an integral part of the activities. 


\section{IDENTIFYING THE PROBLEM, AND THE ROLE OF SOCIOLINGUISTICS}

In England and Wales it has been claimed that the Police and Criminal Evidence Act (PACE) 1984, and the associated implementation of the $\mathrm{PEACE}^{1}$ interviewing model, led to a significant decrease in the number of miscarriages of justice occurring as a result of poorly conducted suspect interviews. However, it is further claimed that PACE had little impact on the interviewing of victims and witnesses, which remained flawed on the grounds that many officers assumed that the interviewing of a co-operative and competent adult witness required little specialist skill (Savage and Milne 2007). The interviewing of suspects is now guided by the Conversation Management model (Shepherd and Griffiths 2013), while the interviewing of significant witnesses is guided by the Enhanced Cognitive Interview (ECI) model (Milne and Bull 1999; Milne 2004). These approaches to investigative interviewing differ vastly from the Reid technique, favoured in the US and a number of other countries, which is characterised by the encouragement of coercive interrogation, and lacks the evidence base from which the methods discussed here have been developed. However, some of the techniques recommended within the UK models do have some equivalence with what is termed the "information gathering" phase of the Reid interview.

While all attempts at improving the process are to be welcomed, there is a notable absence of linguistic research drawn on in the current training programmes. Furthermore, it has been pointed out that there exists a general lack of consistency amongst academics and practitioners about relevant categories for analysing police interview discourse (see for example Oxburgh et al. 2010). Current training programmes have neglected to address some of the issues surrounding the conflict that arises when IRs attempt to engage in the recommended 'personalised' interaction, which must simultaneously fulfil its institutional role of gathering potential criminal evidence. Furthermore, there has been little acknowledgement 
that IRs accomplish a far more diverse set of tasks in the interview room than simply 'questioning.' The approaches informing the current training programmes might also be criticised on the grounds of their assumption of a subjective/objective distinction. The emphasis on adopting strategies which minimize the introduction of 'biased' information implies that the task of isolating one version of events as neutral and objective can be carried out relatively easily. This is not a perspective that is shared by the majority of researchers working within a discourse analytic paradigm (see Auburn et al. 1999).

It could be argued that our activity risks further empowering the dominant group in a context which has been widely noted to have significant potential for disempowering IEs. Why are we not reaching out to IEs and empowering them to develop awareness and resistance strategies for dealing with potentially coercive questioning? The answer is that a comparable, accessible group of witnesses, victims or suspects is simply not available, and the process of assembling such a group - for example through police contact - is fraught with ethical and practical difficulties. At any rate, as maintained by Wodak (1996), there are a number of domains in which changes to discursive practices have the potential to advance the interests of the powerless. Thus, we take up the credible counter-argument that the most effective way of assisting vulnerable IEs is to ensure that interviews are conducted in the most informed manner, and that their voices are heard. Working with practitioners is the most effective method of ensuring that the insights arising from the sociolinguistic research - issues of power, dominance, negotiation and so on - are put to meaningful use in improving the police interview process. This is in line with the position set out by Wiggins and Hepburn (2007) and elsewhere that discursive intervention can be used to provide practitioners with a more analytically informed set of resources, using real-life examples to highlight features of good practice as well as the complexities of how IRs' goals are achieved. Of course, as Willig points out, the effectiveness of this kind of engagement depends upon the willingness of the relevant 
professionals to co-operate: "reform ... must be acceptable to those whose power is grounded in the status quo" (1999: 17).

It has been noted in the past that discourse analysts have generally been reluctant to move beyond critical commentary to active engagement with social and institutional practices, owing in part to an "acute awareness of the dangers associated with a clear commitment to particular policies and practices" (Willig 1999: 1). Few discourse analysts have addressed the issue of application, and even fewer have tackled the formulation of concrete proposals for social interventions (but see e.g. Roberts 2003). The approach we originally took was committed to exposing the ideologically laden nature of discourse and its role in maintaining unequal power relations - that is to say, a critical approach. But we wondered: how could we go about reconciling this agenda with our aspiration to instigate positive change in institutional practices? It was clear that remaining 'critical' while maintaining close engagement with practitioners was a significant challenge. In this chapter we discuss how we overcame these challenges, and we encourage other researchers to consider tackling these obstacles as well.

Like many types of institutional talk, police interview discourse can be characterised as goal-oriented, with restrictions on the turn-taking patterns and allowable contributions of participants; and as being structured and asymmetrical (Drew and Heritage 1992). Police interview interaction has attracted the attention of discourse analysts primarily interested in the effects on discursive patterns of this obviously asymmetrical distribution of power and the goaloriented nature of institutional talk. Research has also focussed on ways in which such relationships and purposes are managed, negotiated and resisted at the local level (see e.g. Haworth 2006; Newbury and Johnson 2006). In interviews with both suspects and witnesses, it is generally the IR who controls the interaction, possessing as they do the authority, invested in them by the institution they represent, to constrain IEs' type and length of turn, and to control the topics discussed. Recently in England and Wales, however, there has been a move towards 
a more IE-led style of interviewing, in which IRs are encouraged to "transfer control" (Milne and Bull 1999), ask fewer questions and allow IEs more space to give their account of events. The police interview is thus a site of tension between the traditional institutional goals of such an interaction, and the more recent recommendations for personalisation. A further clash arises from the mismatch of agendas between participants - in carrying out familiar day-to-day work, professional IRs display awareness and orientation to institutional practices and priorities, while IEs do not generally possess such awareness, and bring conflicting sets of expectations to the interaction (see Stokoe and Edwards 2008; Haworth 2013).

Previous linguistic research in the area of police interviews has commented on the discursive effects of the interaction's dual role and context, and explored numerous aspects of IRs' talk as they pursue their institutional goal of fixing the 'facts' of the case 'on the record' for the benefit of the future 'overhearing' audience (i.e. the Court) (e.g. Heydon 2005; Johnson 2008; Stokoe and Edwards 2008; Haworth 2013). There has also been interest in the processes by which a 'police preferred' version of events is produced as an alternative to the suspect's version, with the observation that this broadly corresponds to fitting reported events into the legal framework of an offence (e.g. Auburn et al. 1999; Heydon 2003; Benneworth 2010; Haworth 2010).

\section{OVERVIEW OF THE RESEARCH}

The original research on which the current activity is based relied upon England and Wales police archive interview data - video recordings of interviews with women reporting rape (MacLeod 2010), and audio recordings of interviews with suspects (Haworth 2009), recorded as a routine part of police investigations (cf. Dickinson, this volume; Innes, this volume, on the use of audio-visual recording methods). We felt that the investigative interview was a site that 
had the potential to yield rich insights into the relevant professional practices, and provided a strong springboard for effective attempts at influencing these practices.

MacLeod's (2010) study investigated the discursive patterns of interactions between police IRs and women reporting rape in significant witness interviews. Data in the form of video-recorded interviews were obtained from an English police force for the purposes of the study. The data were analysed using a multi-method approach, in line with Heydon (2005), incorporating tools from a number of approaches to discourse to reveal patterns of interactional control, negotiation, and interpretation. The study adopted a critical approach, which is to say that as well as describing discursive patterns, it explained them in light of the discourse processes involved in the production and consumption of police interview talk, and commented on the relationship between these discourse processes and the social context in which they occur. A central focus of the study was how IRs draw on specific interactional resources to shape IEs' accounts in particular ways, and this was discussed in relation to the institutional role of the significant witness interview.

The research established that IRs have access to an array of linguistic resources, which they potentially draw on in order to (re)construct the events that are reported, and to exert their influence over the final account. Far from fully and accurately representing the IEs' stated position, 'final versions' often report only on those elements of the account deemed significant by the police. Since what is treated as significant in the treatment of rape cases has repeatedly been shown to rely heavily on unsupported cultural assumptions about rape and its causes (Moore 2009; Antaki, Richardson, Stokoe and Willott, 2015), these practices have serious implications for both the quality of the evidence and for victim care. The findings of the study indicated that there are a number of issues to be addressed in terms of the training currently offered to officers at Level 2 of the Professionalising Investigation Programme (PIP) (NPIA 2009) who intend to conduct significant witness interviews. Furthermore, a need was identified 
to bring the linguistic and discursive processes of negotiation and transformation identified by the study to the attention of the justice system as a whole.

The training materials are also based on Haworth's (2009) study (see also Haworth 2010, 2013), in which she analysed the current role of police-suspect interview discourse in the England and Wales criminal justice system, with a focus on its use as evidence. A central premise is that the interview should be viewed not as an isolated and self-contained discursive event, but as one link in a chain of events which together constitute the criminal justice process. The research examined two aspects: firstly, the format changes undergone by interview data after the interview has taken place, and secondly, how the other links in the chain - both before and after the interview - affect the interview-room interaction itself. It thus examined the police interview as a multi-format, multi-purpose and multi-audience mode of discourse. An interdisciplinary and multi-method discourse-analytic approach was taken to a corpus of police-suspect interviews. The analysis revealed several causes for concern, both in aspects of the interaction in the interview room and in the subsequent treatment of interview material as evidence. Overall, the study demonstrated the need for increased awareness within the criminal justice system of the many linguistic factors affecting interview evidence.

While we acknowledge that the many and varied approaches taken to the data within these two different studies represent differing philosophical frameworks, our concern here is what each of them can offer to practitioners seeking to evaluate their own professional performance. We therefore present the concepts and categories to the end user much like an analytical toolkit.

\section{A SAMPLE ANALYSIS: FOOTING AND AUDIENCE DESIGN}

By way of example, we present here a snapshot of the types of analyses undertaken in these studies which provided important insight into the strategies adopted by interviewing officers in order to achieve the intended goals of the investigative interview. 
The concepts of audience design (Bell 1981) and footing (Goffman 1981) relate to participants' alignment to a message, and orientation to particular roles, either as receivers or producers of talk. As producers, participants can present themselves as the Principal, or the person responsible for the content of the utterance; as the Author, or the creator of the utterance, 'the agent who scripts the lines' (Goffman 1981: 226); or as the Animator, or the physical producer of the utterance. MacLeod (2010) noted that an examination of the roles occupied by participants in the police interview provided a sound basis for identifying the phases of the interview, but that more importantly it had implications for ensuring the interaction is both IEled and adequately personalised, as per ECI guidance.

The effect of the intended recipient of talk has been a concern of sociolinguists for some time, and Bell's (1984) model, accounting for various categories of audience, remains influential. Haworth (2013) demonstrates that the police interview is a poor fit for the model, and that the IR and IE often orientate to different audiences, with potentially serious consequences. Extract 1 demonstrates the significance of these models for police interview discourse.

\section{Extract 1}

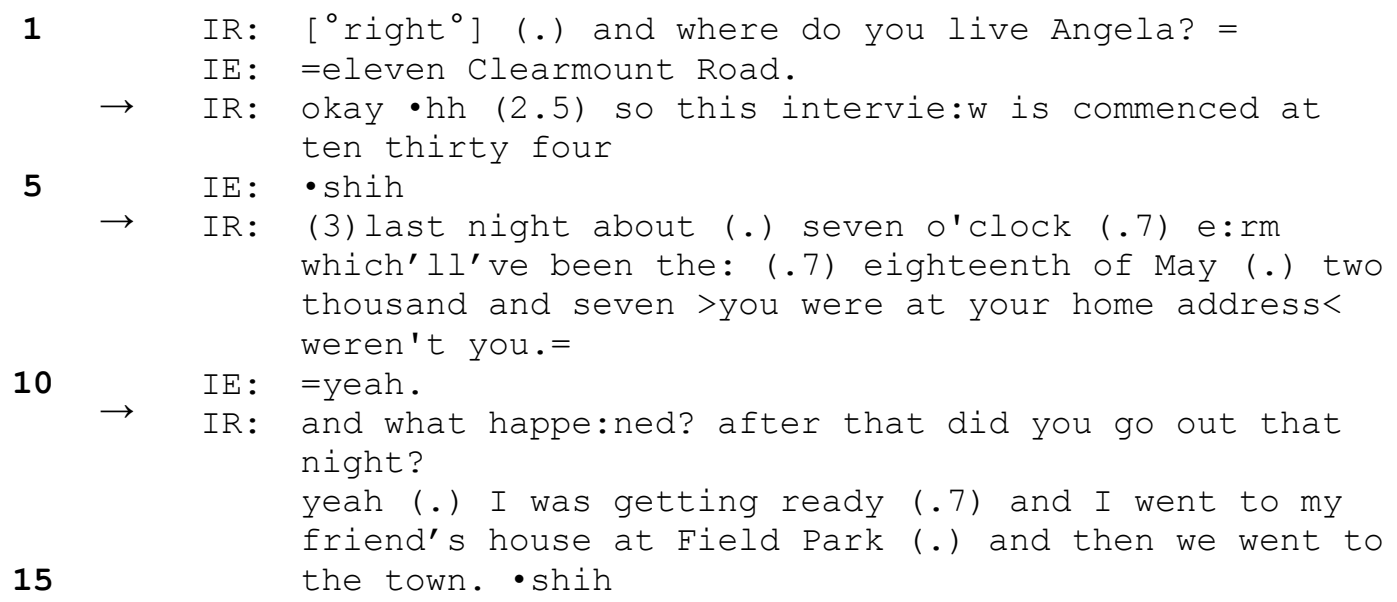


The extract begins as the IR is eliciting a list of personal details from the IE. This in itself reveals the IR's orientation to the institutional context - it seems safe to assume that she is not recording these details for her own purposes, but rather due to institutional requirements. On line 3 the IR uses a metalinguistic comment to begin the 'interview proper,' a clear indication that what has gone before is not considered to belong in this category. The passive construction - use of the word "commenced" - and the specificity of the time reference are all typical of "policespeak" (see e.g. Fox 1993), indicating that the IR is merely animating a message authored by the police institution. On lines 6-7 the IR appears to shift her audience orientation part way through the utterance, repairing "last night" - adequate only for those positioned within the same temporal frame - to "the eighteenth of May (.) two thousand and seven" demonstrating an orientation to an absent addressee. The IR misrepresents her knowledge state with the questions on lines 8-9 and 12-13 - it seems safe to assume that she is already aware that the evening began at the IE's home address, and that she then went out. Rather than seeking unknown information, these questions are designed to elicit confirmation on the record from the IE (see Stokoe and Edwards 2008 for more on "silly questions" in police interviews). There are obvious reasons for these discursive strategies when one considers the institutional role of the interview, and these reasons are familiar to practitioners, as evidenced by trainees' responses to our examples (see below). However, we encourage our trainees to question the extent to which the purpose of such utterances is made clear to IEs, and to consider the potential effects of these discursive peculiarities on IEs' experiences of the investigative interview.

\section{WHAT WE ACHIEVED}

From the findings of the projects described above, we designed a one-day training course with the aim of explicating a wide range of discursive practices relevant to the police interview context. The process of transforming our research findings into useful training materials was 
rather a daunting one, and required us firstly to identify the key theoretical concepts that offered demonstrable insight into interview interaction. These included audience design and footing as discussed above. We then identified extracts from our own police interview data that exemplified these concepts. Our focus was on encouraging IRs to reflect on their own linguistic behaviour in the interview room - we did not intend to deliver a 'how to' guide for best practice interviewing. We began the day with a brief overview of the discipline of Forensic Linguistics, where we explained our areas of interest and the kinds of input forensic linguists have had into the investigative process. We find this provides a good grounding for our subsequent discussion of how linguists' input can be put to meaningful use in the interview room. As well as the broad area of police interviewing, linguists have assisted the police with a wide array of tasks, including training online undercover investigators and offering expertise in cases of disputed authorship of forensic texts. These types of input might prove fruitful avenues to pursue for linguistic researchers seeking to engage with the police in achieving impact.

This session was followed by input on suspect interviewing delivered by Dr Haworth. This session introduced the basics of a number of concepts that have emerged from various approaches to discourse and have provided useful insight into police interview interactions, including turn-taking, speech act theory, and audience design. Crucially, each theory and analytical concept was illustrated with reference to real police-suspect interview data, including audio recordings. Dr MacLeod provided the next session of input, which introduced concepts including footing and formulations - again illustrated with real examples, this time from significant witness interviews. We delivered content through a number of methods - lecturestyle sessions were supplemented with group discussions and hands-on practical data analysis tasks. Attendees were encouraged to participate at will, either with questions, comments or examples from their own professional practice. The final session of the day was devoted to gathering feedback from the course attendees on our training. They were asked to provide this 
through two methods: an individual written feedback form; and a one hour focus group (in quoted feedback below we refer to these as FF and FG respectively).

Most importantly, the input from attendees on the first course guided our design of the second course, and the feedback provided in response to the second course guided our design of the third. Feedback collected at the third course will be pivotal to the design of the next research project, and perhaps more crucially to the development and adaptation of the training to ensure that it is as relevant and useful as possible to practitioners. It is in this way that we can ensure the continuing active involvement of our participants.

At the time of writing, we have completed this activity with three English police forces - South Yorkshire, Sussex, and Greater Manchester - with a total of fifty-two participants. These course attendees were mainly Detective Constable or Detective Sergeant in rank, performing a wide range of roles including on the Adult Protection Team, the Public Protection Unit, the Serious Organised Crime Unit, the Major Investigations Team, and a number of Investigative Trainers. Participants' experience of investigative interviewing ranged from two to thirteen years. All participants were trained to at least PIP Level 2 (core functions) (formerly known as Tier 2), meaning they were qualified to interview victims/witnesses and/or suspects "in relation to serious and complex investigations." Many were trained to PIP Level 2 (specialist roles) (formerly known as Tier 3), meaning they were qualified to conduct “specialist interviews" with victims/witnesses and/or suspects (ACPO 2009: 8). At one force, the one-day input was incorporated into a three-week Advanced Interviewing course, while at the others it served as a standalone session for Advanced suspect and witness IRs, who selfselected to attend.

\section{IMPACT ACHIEVED DURING THE PROCESS}


Firstly, we wish to emphasise that all feedback has been anonymised and we obtained consent from participants to use their contributions in published work. Please note that we have transcribed the focus groups in such a manner as to make the content as clear as possible for readers. They are therefore not transcribed to the same CA standards as the police interview extracts described above. Meanwhile written feedback has been transcribed exactly as it appeared on the handwritten forms.

Overall, the input from participants painted a picture suggesting that sociolinguistic research had a number of important contributions to make to interview training models. While a small number of participants commented that they perceived some overlap between what we presented and previous standard training delivered by psychologists, many more indicated that the input had enabled a fresh and novel insight into their own interviewing practices, and had alerted them to new areas that might warrant their attention in future. For example:

It has provided a different perspective, provided new concepts, and an improved understanding ... It was also an excellent mix of academic and practitioner based knowledge and experience. [Course Attendee, Force 2, FF]

More than anything, it is nice to know what a linguist makes of it, rather than training written by police officers. [Course Attendee, Force 3, FF]

These responses bode well for sociolinguistic researchers who are considering engaging with the police service or similar - there is clear potential for achieving impact in this area.

One clear theme that emerged from the feedback was that we had succeeded in pitching our input as being more concerned with explicating the processes at work than with making recommendations for best practice:

I think it's an awareness and an understanding that you need to know earlier in your career that this could have an influence on what you're doing. I don't think you need to know in 
great detail but you need to have an awareness of it is what I'm trying to say. [Course attendee, Force 1, FG]

While this was wholly in line with our intentions, a number of participants indicated that in fact what they sought was indeed recommendations for good interviewing practice. Asked for their suggestions, many responses reflected a concern for more concrete guidance:

More ... good and bad practice comparisons. [DC, CID, Force 1, FF]

Outlining different styles of interviewing and what potentially has gone wrong and what was particularly good. [DC, SOCU, Force 2, FF]

It is important to note that we do not intend to translate this feedback into a course geared towards offering interviewing guidance, as this is simply not in line with how we position ourselves as linguistic researchers in the field. Rather, the aim is to continue developing the materials with these participants' concerns in mind. We will endeavour to continually challenge attendees to consider the effects of alternative choices.

In terms of the methods of delivery, there was near-consensus at the first force in requesting more practical examples at the expense of some of the more theoretical input (cf. Innes, this volume, on preferences among judges for practical examples):

Much as I found the theory interesting I think a half day front loaded approach is not long enough to fully grasp ideas. Some practical work would help cement theories into practice. [DC, PPU, Force 1, FF]

With this in mind, we endeavoured to incorporate more practical examples into the materials, although compromising on theoretical content while maintaining the necessary focus on describing IR behaviour in sociolinguistic terms was understandably challenging. There are 
obvious benefits in participants observing what actually happens in interviews (even though it has not thus far been possible to have them observing their own behaviour - this is discussed later). Feedback from the second course, designed to incorporate feedback from the first, indicated that we had gone some way to redressing the balance, with suggestions for how the practical examples could be used, as opposed to requests for more of them:

Would be useful to hear more interviews, i.e. tone and pauses, rather than see transcripts. [DC, CID, Force 2, FF]

Get actors to read out your interviews - adds bit of variety. [DC, MCT, Force 2, FF]

The following sections detail how participants responded to particular areas of our sociolinguistic input, and how this input has had a demonstrable impact on participants' professional practice.

\section{PROFESSIONAL LANGUAGE}

The peculiarity of IRs speaking on behalf of the police institution, and addressing future audiences not present in the interview room, appeared to be a new consideration for the participants, including trainers:

We say things like 'at some point this interview may be listened to', but we don't actually analyse it - it takes academics to come in and say 'let's analyse that process what's happening and what yo- what you're doing in the interview to think through those cheap words that you say to people like you know 'this interview at some point might be listened to, so for the purpose of the tape, bla bla bla bla bla'. [Trainer, Force 1, FG] 
The idea of the interview as a complex beast trying to communicate to the potentially vulnerable ill-educated and to the courts at the same time is a useful concept. [DC, SOCU, Force 2, FF]

These participants, and others, indicated to us that our explication of the processes at work when IRs orient to absent audiences is highly valuable for them as they seek to understand their own behaviour. Both the extracts above demonstrate that our input on Audience Design had a strong and immediate impact on how these professionals view their role and practices. There are clearly important practical implications in taking established sociolinguistic theories outside the realm of academia.

Similarly, the seemingly obvious (to an outsider) negative effects of over-use of professional vocabulary for the process of building rapport had apparently only become clear to some participants following our input:

One of the biggest learning points that's come up for me is to talk like a normal person. And I think that's more important and I think if you had that basic understanding earlier on it wouldn't be such a big issue at either level that you could be trained at later on. [Course Attendee, Force 1, FG]

The other point to emerge from the above extract is the level at which we should be offering sociolinguistic training. There appeared to be agreement that practitioners would benefit from engaging with the material at an earlier stage of their careers than that at which we were involved:

If at Tier 2 we'd've been doing things in more plain English we wouldn't have had the week 1 we've had, which we spent all of week 1 trying to undo all the really bad habits 
that we've got into from years of practice at Tier 2 so perhaps that would have been a more natural progression. [Course Attendee, Force 1, FG]

We revisit this concern later in the chapter. The areas discussed here have clearly emerged as salient for participants' own practices. Our input increased awareness of unfamiliar sociolinguistic phenomena, which has had an obvious impact not only on how these professionals view their own role, but also on the way in which they view the training process as a whole.

\section{SPEECH ACT THEORY, OR WHAT IS SAID VERSUS WHAT IS MEANT}

As mentioned earlier, the standard training currently offered makes clear distinctions between types of question, with the distinction being based in the main on grammatical form. Our training highlights utterance function, foregrounding the prolificacy of indirectness and reinforcing the matter of locution not necessarily mapping straightforwardly onto illocution. Or, as we presented it to the course attendees, 'form' versus 'function.'

Once more, exploring this theory allowed for fresh insight into strategies routinely adopted by IRs and equipped participants to reflect critically on existing training models that they had previously followed. In response to the question "what parts of today's training will be most useful for your own interviewing practice?", one participant specified:

Use of pragmatics - that different forms of an expression can have a common function, and that $5 \mathrm{WH}$ is not necessarily the be all and end all. [DC, Advanced Suspect Interviewer, FF, Force 2]

' $5 \mathrm{WH}$ ' refers to a category of question delineated in the current ECI training, which neglects to acknowledge the wide range of interactional tasks a question beginning with 'Wh-' might potentially accomplish. 
I think when you talked as well about the three different questions that are actually all the same question. I think that's really relevant, because you can quite easi- before coming here I didn't really give any real thought to how I phrased a question, or really even think about what I was getting from that question in many ways, and I think that- the way you demonstrated that with three things was quite- made sense to me. [Course Attendee, FG, Force 1]

\section{DISCOURSE MARKERS AND FORMULATIONS, OR WHAT IS SAID VERSUS HOW IT'S SAID}

Discourse markers, or "non obligatory utterance-initial items that function in relation to ongoing talk" (Schiffrin 2003: 57), particularly as prefaces to questions, can be highly revealing of IR's orientations to the ongoing talk in a police interview context. For example, while prefacing a question with 'and...' links it to a preceding question-answer pair and gives the question a routine character (Heritage and Sorjonen 1994), 'but...' prefacing indicates something problematic in the preceding answer, and invites a second attempt. Thus, this is a feature which can be highly revealing of IRs' attitudes towards what they have heard, but had not been explicated to these trainees before our input.

Now, I'll give real consideration to whether I say 'and' or 'but'. [Course Attendee, Force $1, \mathrm{FG}]$

The significance of these choices was evidently not as clear to all participants, with one attendee characterising them as idiolectal rather than strategic or revealing of a particular orientation. In response to the question of what had been least useful about the content, s/he responded: 
Discourse markers as we already learnt about power and control of interviewer and these can be mannerisms. [Course Attendee, Force 2, FF]

Thus, it seems there may still be some way to go in terms of providing input in this area that is meaningful to all participants.

On a related note, the marker so is often indicative of what has been labelled formulation, i.e. utterances that display which interpretation of a prior utterance is being taken up by the recipient, that can then be confirmed or disconfirmed by the original speaker (although given the asymmetry inherent in the police interview setting, it is questionable how far the possibility for disconfirmation is taken up). The preferred response is a confirmation and this is compounded by the fact that formulations are an effective means of preserving the original speaker's principalship for the utterance - to disconfirm a formulation is thus akin to disagreeing with oneself. Many formulations are structurally identifiable by their third turn position, but also by a recurrent syntactic form [(so $)+$ you + verbal/mental process token] (Thornborrow 2002: 97).

Formulations, as explained by Heydon (2003), are an interactional resource frequently drawn on by police officers as a means of negotiating a 'preferred version,' and have a particularly controlling function since they are "a way of leading participants into accepting one's own version of what has transpired" (Heritage and Watson 1979: 136). Formulating necessarily involves the foregrounding of particular aspects of the narrative at the expense of others, and furthermore it has been shown that formulations can and often do include aspects of narrative which were not introduced by the IE (Heydon 2003: 90). Asked what parts of the input will be most useful for their own interviewing practice, one participant responded:

Formulating as inaccurate formulations are dangerous. [Course Attendee, Force 2, FF] 
If we assume that this respondent has the same idea of what constitutes 'danger' in this context, i.e. undue IR influence, then the impact of our input is self-evident. It is encouraging to see that participants have not only been made aware of new concepts and new ways of viewing their interviewing behaviour, but that they have grasped the idea that this is not simply a case of distinguishing between 'good' and 'bad' strategies to adopt - formulating is not poor practice per se, and has many advantages - but an understanding of the risks as well as the benefits can surely only lead to enhancing the skill of the IR.

\section{SUBSEQUENT IMPACT, ACCESSIBILITY AND DISSEMINATION}

In future we plan to return to the three forces at which the training was delivered in order to follow up on the extent to which our input has truly influenced professional practice. However, the feedback gathered through written questionnaires and focus groups indicates a high level of enthusiasm and intention to consider linguistic and discursive matters more carefully in the future, both in relation to their own practices and, for the more senior participants, when feeding back on others' interviews:

Pragmatics and police interviews, impact on witness/ suspect - can now consider this further in planning stage. Being made aware that consideration for forensic linguistics can continually improve your interview and I will consider this when I evaluate any future interviews. [DC MIT, Force 1, FF] (our emphasis)

As well as disseminating the findings of this research to numerous academic conferences, we have been involved with the International Investigative Interviewing Research Group (iIIRG) since its inception in 2007. The iIIRG's membership consists of academics and practitioners at varying levels, including specialist interview advisors, members of the College of Policing, and members of the Association of Chief Police Officers interview steering group, which is responsible for national interviewing policy. It is through involvement with this organisation 
that we were able to foster the strong working relationships and gain the support that allowed for the training activities to take place, and it is through continued involvement that we hope to design and deliver our revised training as an ongoing venture. We would strongly encourage sociolinguistic researchers with an interest in institutional language to seek connections with this iIIRG, which offers unparalleled opportunities for collaboration and the achievement of impact.

We have presented to the iIIRG at their annual conferences, on narrative transformation (2009); footing in the police interview (2010); audience design (2012) and the treatment of IEs' excuses and justifications (2012). We have also raised awareness through contribution to a four-day course entitled Linguistic and Psychological Techniques for Sexual Crime Investigation co-hosted by the University of Birmingham and Aston University in April 2012, the majority of whose delegates were senior police officers involved in training. Several CPD training events for police IRs have taken place at Aston University, with more events scheduled for the near future. Related publications have also appeared in practitioner journals such as The British Journal of Forensic Practice (e.g. MacLeod 2011).

While the ethos and activities of iIIRG represent a unique opportunity for academics and practitioners to engage with each other in a mutually beneficial and genuinely productive relationship, the practitioner membership is largely restricted to relatively senior policing representatives. Dissemination to iIIRG in no way ensures dissemination to professionals at the front line of policing. Likewise, as we discussed above, the sociolinguistic training has so far been restricted to advanced IRs. How should we broaden the scope of our activity and reach the lower ranks? It is clear that this is a concern shared by many of our participants:

I think it would be better delivered at Tier 2 interviewers, increase awareness and teach good practise [sic] from start. [DC, MCT, Force 2, FF] 
It's alright saying we're at the higher level now but in our force certainly Tier 2 s can quite happily interview rapes, and a lot of other serious top end offences on a regular basis. It's not the Tier 3s that would be doing it. [Course Attendee, Force 1, FG]

The Apollo units that predominantly deal with sexual offences but rapes in particular that the lead interviewers are PCs and they tend to be at the moment young in service ... so if it was my job as a Tier 3 I would go and I would sit as second interviewer, which doesn't really sit well with me and we've got a lead interviewer that's got no knowledge and that is crucial evidence it's- and we're not getting the best evidence and- I think we're failing before we're even starting really. [Course Attendee, Force 1, FG]

There were also suggestions for targeting the training even further down the line, to officers interviewing at Level 1 of the Professionalising Investigation Programme (formerly Tier 1), that is those officers who interview victims and witnesses and/or suspects in relation to "priority and volume investigations" (ACPO 2009: 8). On the other hand, others expressed a concern that, pitched at its current level, our training risked posing difficulties for IRs at a lower level:

Maybe it's a bit more of a cultural thing early on I think the input we've had today is relevant at this level and I don't think- if you tried giving a probationer that it would just blow their mind cos they're trying to learn too much. [Trainer, Force 1, FG]

It is clear then that, given our plans for the future (as outlined in the next section), something that will require careful consideration is how - and indeed whether - we adapt the material to suit a less advanced audience. This will be impossible to accomplish without the sustained input of our police colleagues.

\section{FUTURE IMPACT}


In line with Roberts' suggestion that applied linguists are "more likely to have an impact by trying to change practice with practitioners rather than through grand attempts at engineering policy change" (2003: 135), the activity reported here is geared towards engaging closely with interviewing practitioners in a bottom-up process of improving practice. However, there is also the potential, through our ties with iIIRG, to have a much larger impact on national training in the future, just as psychology has done with national police IR training models. One participant commented that the content should be:

Rolled out in some form in general interview training to police. [DS, APT, Force 2, FF]

Comments such as this suggest that practitioners see great potential in the contribution of linguistics to nationwide interviewing training models. According to this participant and a number of others, our input is required at a more basic level than that at which we delivered the level of 'general interview training,' i.e. fairly recent recruits to the police service, involved in interviewing in volume crime investigations. If this were to come to fruition, it would constitute a tangible impact of our research. Police work has, in recent times, become more amenable to the input of academics, so it would seem timely for more sociolinguists to become involved in contributing to the strive for good practice through mutually beneficial engagement such as that described in this chapter. On this basis, we have plans underway to produce a bid for further research funding in order to develop and extend the activities undertaken so far.

We cannot have a clear idea of how the materials are likely to be developed until we commence research collaboration with police partners (nor indeed until the analysis of the research reported here has been finalised). We can, however, glean some potential developments from the contributions of participants in the current activity.

To come on this course everyone's got to do an assessment interview and you've all got to assess it yourselves and you all hand in an interview and a transcript mostly so it's like- 
we'll assess you to bring you on cos- everybody here's been assessed so they all come on the course assessed but why can't we not then just send you that transcript I mean you don't have to use a whole lot of it you'd just be looking at a bit of it and then it sort of personalises what you've then done. [Trainer, Force 1, FG]

This comment, and the general consensus that subsequently unfolded in the room, suggest that participants are keen to observe and reflect on their own use of particular discursive strategies. The feeling seems to be that this will enhance the impact of merely seeing these strategies in action in the interview rooms of police colleagues remote in time and space. The suggestion in this extract is that transcripts from genuine interviews that course attendees had previously conducted be forwarded to us in advance of the session. We could then analyse these and incorporate extracts into the course materials. This suggestion was made several times and it seems fairly intuitive that this will allow for a deeper understanding of the relationship between sociolinguistic theory and individual professional development. The question of whether this is a realistic course of action for us, given the time constraints and the unpredictability of the data that we would actually receive, is the subject of ongoing debate, and we continue to consider ways in which this idea could be incorporated. One possibility is that attendees look at their own historical interviews as a hands-on analysis task, identifying how the various theories are relevant to their practice and reporting back to the group. In any case, our future training will always be guided by the participants and their own experiences.

\section{CONCLUSION}

In this chapter we have demonstrated the potential for sociolinguistic research to achieve widereaching and meaningful impact for professional practice. We repackaged findings from our discourse analytical research into interaction in police interviews as training materials, by using real examples from police interviews to exemplify key analytical points. Our aim from the 
outset was to explicate for IRs the strategies they adopt during interviews and demonstrate the effects of these choices. We elicited input from the course participants and have used this in an ongoing process of evaluation and development.

One important issue to note is that our activities have been on a very small scale; the issue of making the findings both accessible and relevant to all professionals undertaking investigative interviews cannot be overestimated. It is one thing to engage a handful of enthusiastic training co-ordinators - who by their very involvement with IIIRG are obviously accommodating to the potential for academic research to inform investigative practice. It is quite another to penetrate those areas of the police service that have yet to acknowledge the mutually beneficial potential of these kinds of collaboration. The forty-three territorial police forces of England and Wales are each responsible for their own training provision, and thus a highly productive relationship with Greater Manchester Police is no predictor of success with other forces. It may be too much to expect that the resounding success of our collaborative efforts will either trickle down to the lower ranks, or out to colleagues in less progressive forces.

That said, we have identified a clear requirement both for more sociolinguistic research in the area of police interviewing and for more widespread engagement with police practitioners in general. Within the scope of forensic linguistics, there are myriad opportunities for engagement between sociolinguistic researchers and the police. As Roberts (2003: 132) notes:

[I]t is not easy to work out what difference our research has made to those outside our world, but at least we should be asking ourselves the question and contemplating the conditions which might produce a satisfying answer for both the professional groups we work with and ourselves. 
We hope that we can build on these first steps and these initial questions and work towards valuable outcomes for all parties.

\section{ACKNOWLEDGEMENTS}

We would like to thank the British Association of Applied Linguistics' 'Applying Linguistics' fund for recognising the potential of this project and providing us with the funding required to carry it out. We would also like to thank Sussex Police, South Yorkshire Police, and Greater Manchester Police for their continuing enthusiasm, and for the attention and active engagement of the trainees and trainers at all three forces. We look forward to being involved with these organisations for many years to come. Lastly we would like to express our gratitude to the editors, and the two anonymous reviewers, for all their work in helping us to refine this chapter.

\section{NOTES}

1. A mnemonic for the recommended structure of any interview, PEACE stands for Plan and Prepare, Engage and Explain, obtain an Account, Closure and Evaluation.

\section{REFERENCES}

ACPO (Association of Chief Police Officers). 2009. National Investigative Interviewing Strategy. Accessed 26 March 2015. Available from: http://www.acpo.police.uk/documents/crime/2009/200901CRINSI01.pdf.

Antaki, Charles, Emma Richardson, Elizabeth Stokoe and Sara Willott. 2015. "Police interviews with vulnerable people alleging sexual assault: Probing inconsistency and questioning conduct.” Journal of Sociolinguistics 19 (3): 328 - 350.

Auburn, Timothy, Susan Lea, and Susan Drake. 1999. “'It's your opportunity to be truthful': Disbelief, mundane reasoning and the investigation of crime." In Applied Discourse Analysis: Social and Psychological Interventions, ed. by Carla Willig, 44-65. Buckingham: Open University Press.

Bell, Allan. 1984. "Language style as audience design.” Language in Society 13 (2): 145-204. 
Benneworth, Kelly. 2010. "Negotiating paedophilia in the investigative interview: The construction of sexual offences against children." In The Routledge Handbook of Forensic Linguistics, ed. by Malcolm Couthard and Alison Johnson, 139-154. Oxon: Routledge.

Crown Prosecution Service. 2007. "Video recording interviews with vulnerable and significant witnesses: Revised guidance." Accessed 26 March 2015. Available from: https://www.cambs.police.uk/about/foi/policies/Vulnerable\%20etc\%20Witness\%20 Interviews\%20Policy.pdf.

Drew, Paul, and John Heritage. (eds.) 1992. Talk at Work: Interaction in Institutional Settings. Cambridge: Cambridge University Press.

Fox, Gwyneth. 1993. “A comparison of 'policespeak' and 'normalspeak': A preliminary study." In Techniques of Description: Spoken and Written Discourse, ed. by John M. Sinclair, Michael Hoey and Gwyneth Fox, 183-195. Oxon: Routledge.

Gibbons, John. 2003. Forensic Linguistics: An Introduction to Language in the Justice System. Oxford: Blackwell.

Goffman, Erving. 1981. Forms of Talk. Philadelphia: University of Pennsylvania Press.

Haworth, Kate. 2006. "The dynamics of power and resistance in police interview discourse." Discourse and Society 17 (6): 739-759.

Haworth, Kate. 2009. An Analysis of Police Interview Discourse and its Role(s) in the Judicial Process. $\mathrm{PhD}$ thesis. University of Nottingham.

Haworth, Kate. 2010. "Police interviews in the judicial process: Police interviews as evidence." In The Routledge Handbook of Forensic Linguistics, ed. by Malcolm Couthard and Alison Johnson, 169-184. Oxon: Routledge.

Haworth, Kate. 2013. "Audience design in the police interview: The interactional and judicial consequences of audience orientation." Language in Society 42 (1): 45-69. 
Heritage, John, and Marja-Leena Sorjonen. 1994. "Constituting and maintaining activities across sequences: And-prefacing as a feature of question design.” Language in Society 23 (1): 1-29.

Heritage, John, and D. Rodney Watson. 1979. "Formulations as conversational objects." In Everyday Language: Studies in Ethnomethodology, ed. by George Psathas, 123-162. New York: Irvington.

Heydon, Georgina. 2003. “"Now I didn't mean to break his teeth': Applying topic management to problems of power asymmetry and voluntary confessions.” In Applied Linguistics and Communities of Practice, ed. by Srikant Sarangi and Theo van Leeuwen, 81-149. London: Continuum.

Heydon, Georgina. 2005. The Language of Police Interviewing: A Critical Analysis. Basingstoke: Palgrave Macmillan.

Johnson, Alison. 2008. “'From where we're sat...': Negotiating narrative transformation through interaction in police interviews with suspects." Text and Talk 28 (3): 327-349.

MacLeod, Nicci. 2010. Police Interviews with Women Reporting Rape: A Critical Discourse Analysis. $\mathrm{PhD}$ thesis, Aston University.

MacLeod, Nicci. 2011. "Risks and benefits of selective (re)presentation of interviewees' talk: Some insights from discourse analysis.” British Journal of Forensic Practice 13 (2): 95102.

Milne, Rebecca. 2004. The Enhanced Cognitive Interview. Accessed 26 March 2015. Available from: https://www.how2ask.nl/wp-content/uploads/downloads/2011/09/ Guide-cognitive-interviewing.doc.

Milne, Rebecca, and Ray Bull. 1999. Investigative Interviewing: Psychology and Practice. Chichester: Wiley. 
National Policing Improvement Agency. 2009. National Investigative Interviewing Strategy. $\begin{array}{lllll}\text { Accessed } & 26 & \text { March } & 2015 . & \text { Available }\end{array}$ http://www.acpo.police.uk/documents/crime/2009/200901CRINSI01.pdf.

Newbury, Phillip, and Alison Johnson. 2006. "Suspects' resistance to constraining and coercive questioning strategies in the police interview." International Journal of Speech, Language and the Law 13 (2): 213-240.

NPIA (National Policing Improvement Agency). 2009. "Professionalising investigation programme (PIP)". Accessed 26 March 2015. Available from: http://webarchive.nationalarchives.gov.uk/20081230144213/http://www.npia.police.uk/ en/10093.htm.

ONS (Office for National Statistics). 2011. Crime in England and Wales, Quarterly First Release to December 2011. Accessed 26 March 2015. Available from: http://www.ons.gov.uk/ons/dcp171778_263244.pdf.

Oxburgh, Gavin, Trond Myklebust, and Tim Grant. 2010. "The question of question types in police interviews: A review of the literature from a psychological and linguistic perspective.” International Journal of Speech, Language and the Law 17 (1): 45-66.

Roberts, Celia. 2003. “Applied linguistics applied.” In Applied Linguistics and Communities of Practice, ed. by Srikant Sarangi and Theo van Leeuwen, 132-149. London: Continuum.

Savage, Stephen P., and Rebecca Milne. 2007. "Miscarriages of justice." In Handbook of Criminal Investigation, ed. by Tim Newburn, Tom Williamson and Alan Wright, 610627. Cullompton: Willan.

Shepherd, Eric, and Andy Griffiths. 2013. Investigative Interviewing: The Conversation Management Approach, 2nd ed. Oxford: Oxford University Press. 
Stern, Baroness Vivien. 2010. The Stern Review. Accessed 26 March 2015. Available from: http://www.equalities.gov.uk/PDF/Stern_Review_acc_FINAL.pdf.

Stokoe, Elizabeth, and Derek Edwards. 2008. “'Did you have permission to smash your neighbour's door?': Silly questions and their answers in police suspect interrogations." Discourse Studies 10 (1): 89-111.

Thornborrow, Joanna. 2002. Power Talk: Language and Interaction in Institutional Discourse. London: Longman.

Wheatcroft, Jacqueline M., Graham F. Wagstaff, and Katie Russell. 2013. "Specialist police interviewer perceptions of the enhanced cognitive interview: Usefulness, confidence and witness reliability." Police Practice and Research: An International Journal 15 (6): 505518.

Sally Wiggins, and Alexa Hepburn. 2007. "Discursive research: Applications and implications." In Discursive Research in Practice: New Approaches to Psychology in Interaction, ed. by Alexa Hepburn and Sally Wiggens, 281-291. Cambridge: Cambridge University Press.

Willig, Celia. (ed.) 1999. Applied Discourse Analysis: Social and Psychological Interventions. Buckingham: Open University Press.

Wodak, Ruth. 1996. Disorders of Discourse. Harlow: Longman. 